\title{
Development and Evaluation of Different Rotary Slit Cutters under Controlled Condition
}

\author{
Mohammad Quasim ${ }^{1}$, A.K. Shrivastava ${ }^{2}$, S.K. Rautaray ${ }^{3}$ and Avinash Kumar Gautam ${ }^{2 *}$ \\ ${ }^{1} C A E, I G K V V$, Raipur, India \\ ${ }^{2}$ Department. of FMPE, CAE, JNKVV, Jabalpur, India \\ ${ }^{3}$ C. I. A.E., Bhopal, India \\ *Corresponding author
}

A B S T R A C T

Zero-Till-Slit tillage and seeding machine was designed and developed for fulfilling the requirements of conservation agriculture. The rotary zero-till-slit tillage and seeding machine were developed for zero-till seeding in straw fields after grain combine

Keywords

Rotary Slit Cutters, Zero-Till-Slit

tillage,

Rotary knife

Article Info

Accepted:

04 April 2019

Available Online:

10 May 2019 harvester's operation. The combined tillage and seeding machine were equipped with seven units of rotary slit cutters as a key component. In the present study, four different shapes of rotary slit cutters were evaluated in the soil-bin laboratory for different forces acting on the rotary slit cutter blade. The four blade shapes were trapezoidal, triangular, knife section with full-length sharp edge and knife section with a pointed tip and tapered sharp edge. The performance evaluation of four rotary blade shapes of slit cutters was carried out in soil-bin at ICAR - C.I.A.E., Bhopal under controlled soil conditions. Lower values of horizontal force $(\mathrm{N})$, vertical force $(\mathrm{N})$, and torque exerted $(\mathrm{N}-\mathrm{m})$ were found in the trapezoidal shape of slit cutter compared to triangular, knife section with full-length sharp edge and knife section with a pointed tip and tapered sharp edge. A horizontal force $(\mathrm{N})$, vertical force $(\mathrm{N})$, torque exerted $(\mathrm{N}-\mathrm{m})$ were found increased as forwarding speed (S), rotational speed (RS), and depth of cut of rotary slit cutter blade increases in the four shapes of rotary blade of slit cutters. The effect of blade shape of slit cutter (C), forward speed (S), rotational speed (RS) and depth of cut (d) on the horizontal force, vertical force, torque exerted and depth of cut were found highly significant.

\section{Introduction}

In India, the importance of 'minimum soil disturbance' was realized about three decades ago. But, it could not be readily adopted due to unavailability of suitable seeding machine. The development of a zero-till drill at GBPUA\&T, Pantnagar and its fine-tuning paved the way for agricultural transformations, particularly in rice-wheat systems (NATP, 2002). Chaudhary and Singh (2002) reported that the zero-till system saved fuel and time as compared to strip and conventional systems. The saving in irrigation for zero-till was 34 and $47 \%$ over strip-till and conventional system. Fiszer et al., (2007) reported that no-ploughing method resulted in a $9.5 \%$ higher yield than the traditional 
seedbed preparation. An analysis of the crop production cost showed that no-ploughing was $33.7 \%$ lower than the traditional method. Singh and Singh (2006) reported that about $67.8 \%$ more yield was achieved by seeding lentil with the zero-till drill as compared to conventional tillage method.

Four different shapes of rotary slit cutters were tested in soil dynamics laboratory under controlled soil-bin conditions for evaluation of their performances. Rotary slit cutters were used for the opening of narrow slits on the seedbed for easy and anti-clogging movement of seeding shoe in straw contained field conditions. Based on the soil-bin study, development of rotary zero-till-slit seed drill was carried out for combined tillage and seeding operation while conserving soil moisture in-situ (Figure 1). The tillage and seeding machine was equipped with seven units of slit cutters mounted on a common shaft for cutting the surface straw/stubbles and opening the narrow and shallow depth slits (Figure 2). The primary openers were able to open slits having width and depth of $10 \mathrm{~mm}$ and $100 \mathrm{~mm}$ respectively. Secondary furrow openers of seed drill have followed behind the slit openers were for placing seed and fertilizer into the slit made in the soil. The rotary cutters were powered by tractor p. t. o. and metering of seeds behind the slits was through fluted roller mechanism powered by the ground drive wheel of the machine. The main function of the eight spring loaded press wheels were to press-hold the loose straw for smooth cutting (Figure 1). Spring-loaded press wheels were positioned at both sides of each rotary cutter unit which was mounted to the main frame at the front end.

\section{Materials and Methods}

The slit cutter rotary blades of different shape were designed and fabricated viz. trapezoidal (sharp edge) shape $\left(\mathrm{C}_{1}\right)$, triangular (serrated) shape $\left(\mathrm{C}_{2}\right)$, knife section (full-length sharp edge) shape $\left(\mathrm{C}_{3}\right)$ and knife section tapered sharp edge shape $\left(\mathrm{C}_{4}\right)$.

\section{Trapezoidal shape slit cutter blade}

The trapezoidal shape slit cutter was designed and fabricated as shown in Figure 3 having dimensions as (L X W X t) of $85 \times 75 \times 8$ $\mathrm{mm}$. The base width of the trapezoidal blade was $75 \mathrm{~mm}$ with two holes of diameter $6 \mathrm{~mm}$. The width of the blade at tip end was $15 \mathrm{~mm}$ with a tapered edge. The side length of the blade was also tapered for $60 \mathrm{~mm}$ length. Six no of trapezoidal blades were fitted in each rotary flange with bolts and nuts (Figure 3). The diameter of the rotor with trapezoidal blades was $427 \mathrm{~mm}$ in the mounted position.

\section{Triangular shape slit cutter blade}

The triangular shape slit cutter was designed and fabricated as shown in Figure 4 having dimensions ( $\mathrm{L} \mathrm{X} \mathrm{W} \mathrm{X} \mathrm{t)} \mathrm{as} 85 \mathrm{X} 75 \times 8 \mathrm{~mm}$. The base width of the triangular blade was 75 $\mathrm{mm}$ having two holes of diameter $6 \mathrm{~mm}$. The width of the triangular blade at the tip was 2 $\mathrm{mm}$ with a tapered sharp edge. The two sides of the blade perform the cutting of slits which are tapered and sharp in $60 \mathrm{~mm}$ side length from the flange rotor. Six no of triangular blades were mounted on each flange. The diameter of the triangular rotary blade was $427 \mathrm{~mm}$ when six triangular blades were mounted.

Knife shape (full-length sharp edge) slit cutter blade

Rotary knife section was used as slit cutters when six knives were fitted to $23 \mathrm{~cm}$ diameter circular flange (Figure 5). These knives were fitted with the help of two bolts and nuts positioned to make $35^{\circ}$ inclined with respect to the horizontal line. The holes of $6 \mathrm{~mm}$ diameter were made in such a way as that the 
triangular blades were fitted at an inclination of $35^{\circ}$ (Figure 5). The diameter of the rotor with rotary knife section blades was $412 \mathrm{~mm}$. The dimensions ( $\mathrm{L} \mathrm{X} \mathrm{W} \mathrm{X} \mathrm{t)} \mathrm{of} \mathrm{knife} \mathrm{section}$ blades were 175 X 40 X $8 \mathrm{~mm}$. The length and width of the sharp edge of the knife section were $100 \times 20 \mathrm{~mm}$ with a taper at the end (Figure 5).

\section{Knife shape (pointed tip and tapered edge) slit cutter blade}

The six rotary knives having pointed tip and tapered sharp edge were fitted to the rotary flange at an angle of $30^{\circ}$ to the horizontal line (Figure 6). The diameter of the flange was $310 \mathrm{~mm}$ with a total rotor diameter of 405 mm when six knives blades were mounted. The length, width and thickness of knife section blade (L X W x t) were 130 X 30 X $15 \mathrm{~mm}$. The length of the sharp edge of knife section up to the pointed tip which performed the cutting of soil slit was $50 \mathrm{~mm}$. The full length of a knife blade was utilized for slit cutting and was having $90 \mathrm{~mm}$ width (Figure $6)$.

\section{Soil-bin facility}

The soil bin of rectangular shape having size 16.0 X 2.5 X 1.0 meters (L X W X H) was constructed of a concrete structure. It holds enough soil volume to facilitate testing of full-size agricultural equipment without side effects and variability (Figure 7). On the two longer sidewalls of the soil bin, I-section metallic beams were reinforced in concrete to facilitate movement of tool carriage. Arrangements were made to facilitate testing of agricultural implements/tools under controlled soil conditions. On the shorter sidewalls, driving shaft and chain sprocket arrangement had been mounted, which provided motion to the tool carriage (Figure 8). The soil bin also contained pipeline arrangement on the sidewalls for watering and removal of excess water for conducting experiments pertaining to different soil moisture conditions. On either end of both Ibeams, limit or stop switch have been provided. Limit switches changed the direction of motion of the carriage at the ends to make it auto-reversing and stop-switches prevented any accidental situation in case the limit switches fail to activate in its autoreversing mechanism.

The soil bin system was provided with electronic measuring, computing and analysis system to measure, record and analyze the dependent variables for evaluation of the performance of various agricultural equipment. A control panel with computerized desk (Figure 9) facilitates remote operation of a carriage, data logging and analysis. The instrumentation provided in soil bin system facilitates the measurement of the following independent and dependent parameters acting on a tool during its operation through electronic sensors.

Horizontal, vertical and lateral forces Torque exerted on rotary slit opener Linear speed of rotary slit opener Rotational speed of rotary slit opener Depth of operation of rotary slit opener (d)

\section{Evaluation of rotary slit cutters in soil bin}

Four rotary slit cutters having different shapes were evaluated as per the statistical plan of the study.

\section{(a) Independent variables}

(i) Types of slit cutter (C)

$\mathrm{C}_{1}=$ Trapezoidal section

$\mathrm{C}_{2}=$ Triangular serrated section

$\mathrm{C}_{3}=$ Knife section full length sharp edge

$\mathrm{C}_{4}=$ Knife section pointed tip and tapered sharp edge 
(ii) Forward speed of operation $(\mathrm{km} / \mathrm{h})$

$\begin{array}{lll}\mathrm{S}_{1} & = & 1.0 \\ \mathrm{~S}_{2} & = & 1.5 \\ \mathrm{~S}_{3} & = & 2.0\end{array}$

(iii) Rotational speed of the slit cutter (rpm)

$\mathrm{RS}_{1}=150$

$\mathrm{RS}_{2}=200$

$\mathrm{RS}_{3}=250$

(iv) Depth of cut of slit (tillage) (cm)

$\begin{array}{lll}\mathrm{d}_{1} & = & 1 \\ \mathrm{~d}_{2} & = & 3 \\ \mathrm{~d}_{3} & = & 5\end{array}$

\section{(b) Dependent variables}

(i) Horizontal force $(\mathrm{N})$

(ii) Vertical force, $(\mathrm{N})$

(iii) Torque, $(\mathrm{N}-\mathrm{m})$

(iv) Width of slit opened (cm)

Statistical layout for the experiments was made for studies on different rotary slit cutters following split-split-split plot design. In the layout of an experiment, the depth of cut by slit cutters (d) of the blade was kept in the sub-sub-sub plot for maximum precision, rotational speed (RS) in sub-subplot, forward speed (S) in the subplot and different sections of rotary slit cutter $(\mathrm{C})$ in the main plot.

The different shapes of rotary slit cutter (C) was the main design consideration which was changed with another section of rotary slit cutter (C) after complete observations were made for one section of rotary slit cutter (C) in laboratory tests by varying the forward speed (S), rotational speed (RS), and depth of cut (d) as independent variables. The data recorded were subjected to four-way ANOVA to evaluate different sections of rotary slit cutter (C) for a width of slit opened and multiple

\section{Results and Discussion}

\section{Effect of blade shape of slit cutter on horizontal force, $\mathbf{N}$}

The horizontal force $(\mathrm{N})$ was found increased as the forward speed increases in the four rotary blades of slit cutter, at the three rotational speeds and the three depths of cut (Table 1). The horizontal force $(\mathrm{N})$ was found increased as the depth of cut increases at one rotational speed and similarly, the horizontal force $(\mathrm{N})$ was also found increased as the rotational speed increases at one depth of cut (Table 1).

Lower values of horizontal force $(\mathrm{N})$ were found at the three forward speeds (1.0, 1.5 1and $2.0 \mathrm{~km} / \mathrm{h}$ ) in trapezoidal shape of slit cutter blades followed by triangular shape blade, knife section (full-length sharp edge) and highest in knife section (pointed tip and tapered sharp edge) (Table 1). Slit cutter blade section (C), forward speed (S), rotational speed (RS), depth of cut (d), twofactor interactions, three-factor interactions and four-factor interaction were found highly significant at $5 \%$ and $1 \%$ level.

\section{Effect of blade shape of slit cutter on the vertical force, $\mathbf{N}$}

The vertical force $(\mathrm{N})$ was found increased as the forward speed increases in the four rotary blades of slit cutter, at the three rotational speeds and the three depths of cut (Table 2). Lower values of vertical force $(\mathrm{N})$ were found at the three forward speeds (1.0, 1.5 1and 2.0 $\mathrm{km} / \mathrm{h}$ ) in trapezoidal shape of slit cutter blades followed by triangular shape blade, knife section (full-length sharp edge) and highest in knife section (pointed tip and tapered sharp edge) (Table 2). The vertical force $(\mathrm{N})$ was found increased as the depth of cut increases at one rotational speed and similarly, the 
vertical force $(\mathrm{N})$ was also found increased as the rotational speed increases at one depth of cut (Table 2). The values of vertical force $(\mathrm{N})$ were negative because the direction of the vertical force is an upward direction due to the resistance of soil reaction.

The effect of slit cutter blade section (C), forward speed (S), rotational speed (RS) and depth of cut (d) on the vertical force was found highly significant at $5 \%$ and $1 \%$ level. The two-factor interaction of $\mathrm{RS}^{*} \mathrm{~d}$ and threefactor interaction of $\mathrm{C}^{*} \mathrm{RS} \mathrm{S}^{*} \mathrm{~d}$ were found highly significant at $1 \%$ level and significant at $5 \%$ level respectively. The two-factor interactions of $C^{*} S, C^{*} R S, C^{*} d, S * R S, S^{*} d$; three-factor interactions of $C^{*} S * R S, C * S * d$, $\mathrm{S}^{*} \mathrm{RS} * \mathrm{~d}$ and four-factor interaction of $\mathrm{C} * \mathrm{~S} * \mathrm{RS} * \mathrm{~d}$ were found non-significant.

\section{Effect of blade shape of slit cutter on torque $(\mathrm{N}-\mathrm{m})$}

The torque forces exerted $(\mathrm{N}-\mathrm{m})$ were found increased as the forward speed increases in the four rotary slit cutter blades at the three rotational speeds and the three depths of cut tested (Table 3$)$. The torque exerted $(\mathrm{N}-\mathrm{m})$ was found increased as the depth of cut increases at one rotational speed and similarly, the torque exerted $(\mathrm{N}-\mathrm{m})$ was also found increased as the rotational speed increases at one depth of cut (Table 3). Lower torque force $(\mathrm{N}-\mathrm{m})$ was exerted at the three forward speeds $(1.0,1.5$ and $2.0 \mathrm{~km} / \mathrm{h})$ in trapezoidal shape of slit cutter blades followed by triangular shape blade, knife section (full-length sharp edge) and highest in knife section (pointed tip and tapered sharp edge) (Table 3 ).

The effect of slit cutter blade section (C), forward speed $(\mathrm{S})$, rotational speed (RS) and depth of cut (d) on torque force was found highly significant at $5 \%$ and $1 \%$ level. The two-factor interactions (except $\mathrm{C}^{*} \mathrm{~S}$ ), three- factor interactions and four-factor interaction were also found highly significant at $5 \%$ and $1 \%$ level.

\section{Effect of blade shape of slit cutters on a width of slit cut (mm)}

The thickness of rotary blades of four different shapes of slit cutters was kept $8 \mathrm{~mm}$. The soil moisture content in the soil bin was maintained at around $15 \pm 1$ per cent. The data were recorded for a width of the slit cut by the four rotary blades of different shapes of slit cutter at the three forward speeds and other operational parameters i. e. at the three rotational speeds (rpm) and the three depths of $(\mathrm{cm})$ (Table 4).

The wide dimensions of slits were opened in case of trapezoidal shape of slit cutter blade followed by triangular shape blade, knife section (full length sharp edge) and knife section (pointed tip and tapered sharp edge) except in few cases where knife section blades have opened wider slits compared to triangular shape blade slit cutter (Table 4). The wide width of slit cut $(\mathrm{mm})$ were found decreased as the forward speed increases (1.0, 1.5 and $2.0 \mathrm{~km} / \mathrm{h}$ ) in the four shapes of rotary blade slit cutters (Table 4).

The width of slit cut (mm) was also found increased as the rotational speed increases and depth of cut of blades increases in the four blade sections of rotary slit cutter, at the three rotational speeds and at the three depths of cut (Table 4). The width of slit opened ( $\mathrm{mm}$ ) was also found increased in the combination where the depth of cut and rotational speed increases at one rotational speed and at one depth of cut respectively (Table 4).

The effect of slit cutter blade section (C), forward speed $(\mathrm{S})$, rotational speed (RS) and depth of cut (d) on a width of slit cut (mm) was found highly significant at $5 \%$ and $1 \%$ 
level. The two-factor interactions of $\mathrm{C} * \mathrm{RS}$, $\mathrm{S} * \mathrm{RS}, \mathrm{RS} * \mathrm{~d}$ and three-factor interactions of $\mathrm{C}^{*} \mathrm{RS} * \mathrm{~d}$ and $\mathrm{S} * \mathrm{RS} * \mathrm{~d}$ were found highly significant at $5 \%$ and $1 \%$ level whereas twofactor interaction of $\mathrm{C}^{*} \mathrm{~d}$ was found significant at $5 \%$ level only. The two-factor interaction of $S^{*}$; t three-factor interaction of $\mathrm{C} * \mathrm{~S} * \mathrm{RS}$, and $\mathrm{C} * \mathrm{~S} * \mathrm{~d}$ and four-factor interaction of $C * S * R S^{*} d$ were found nonsignificant.

Table.1 Average values of horizontal force data for different slit cutters at different forward speeds, rotational speeds and depth of cut

\begin{tabular}{|c|c|c|c|c|c|c|c|c|c|c|c|c|c|}
\hline \multirow[t]{2}{*}{$\begin{array}{l}\text { Rot. } \\
\text { Speed }\end{array}$} & \multirow[t]{2}{*}{$\begin{array}{l}\text { Depth } \\
\text { of cut }\end{array}$} & \multicolumn{3}{|c|}{ Trapezoidal } & \multicolumn{3}{|c|}{ Triangular } & \multicolumn{3}{|c|}{$\begin{array}{l}\text { Knife (Full length } \\
\text { sharp) }\end{array}$} & \multicolumn{3}{|c|}{$\begin{array}{c}\text { Knife (Tapered } \\
\text { sharp edge) }\end{array}$} \\
\hline & & 1.0 & 1.5 & 2.0 & 1.0 & 1.5 & 2.0 & 1.0 & 1.5 & 2.0 & 1.0 & 1.5 & 2.0 \\
\hline \multirow[t]{3}{*}{150} & 1 & 12.5 & 13.3 & 14 & 13.6 & 14.4 & 15.1 & 14 & 14.4 & 15.3 & 13.9 & 14.7 & 15.6 \\
\hline & 3 & 16.7 & 17.2 & 18.1 & 17.8 & 18.2 & 18.9 & 18.1 & 18.9 & 19.4 & 19.1 & 19.2 & 19.6 \\
\hline & 5 & 19.7 & 20.1 & 20.5 & 20.2 & 20.7 & 20.8 & 21.3 & 21.8 & 22 & 22.1 & 22.4 & 22.7 \\
\hline \multirow[t]{3}{*}{200} & 1 & 22.1 & 22 & 22.7 & 21.2 & 21.6 & 23 & 22.3 & 22.6 & 23.2 & 23.2 & 23.6 & 23.9 \\
\hline & 3 & 24.3 & 28.2 & 25.1 & 25.2 & 25.5 & 25.8 & 26 & 25.8 & 26.2 & 27.2 & 27.5 & 27.9 \\
\hline & 5 & 27.6 & 28 & 28.4 & 28.6 & 29.1 & 28.4 & 29.2 & 29.6 & 30 & 30.1 & 30.6 & 30.8 \\
\hline \multirow[t]{3}{*}{250} & 1 & 31.2 & 31.8 & 31.9 & 32.2 & 32.9 & 33.3 & 33.2 & 33.6 & 33.9 & 34.1 & 34.5 & 34.7 \\
\hline & 3 & 34.1 & 34.5 & 34.9 & 35.1 & 35.5 & 35.8 & 36 & 36.5 & 36.9 & 37.1 & 37.4 & 37.9 \\
\hline & 5 & 37.1 & 37.5 & 37.8 & 38.1 & 38.5 & 38.8 & 39.1 & 39.5 & 39.8 & 40.1 & 40.5 & 40.9 \\
\hline
\end{tabular}

Table.2 Average values of vertical force data for different slit cutters at different forward speeds, rotational speeds and depth of cut

\begin{tabular}{|c|c|c|c|c|c|c|c|c|c|c|c|c|c|}
\hline \multirow[t]{2}{*}{$\begin{array}{l}\text { Rot. } \\
\text { Speed }\end{array}$} & \multirow[t]{2}{*}{$\begin{array}{l}\text { Depth } \\
\text { of cut }\end{array}$} & \multicolumn{3}{|c|}{ Trapezoidal } & \multicolumn{3}{|c|}{ Triangular } & \multicolumn{3}{|c|}{$\begin{array}{l}\text { Knife (Full length } \\
\text { sharp) }\end{array}$} & \multicolumn{3}{|c|}{$\begin{array}{c}\text { Knife (Tapered } \\
\text { sharp edge) }\end{array}$} \\
\hline & & 1.0 & 1.5 & 2.0 & 1.0 & 1.5 & 2.0 & 1.0 & 1.5 & 2.0 & 1.0 & 1.5 & 2.0 \\
\hline \multirow[t]{3}{*}{150} & 1 & 4.1 & 4.2 & 4.5 & 5.0 & 5.3 & 5.7 & 5.6 & 6.4 & 7.0 & 6.2 & 6.9 & 7.5 \\
\hline & 3 & 5.5 & 5.9 & 6.3 & 6.1 & 6.9 & 7.4 & 6.8 & 7.3 & 8.0 & 7.1 & 7.8 & 8.3 \\
\hline & 5 & 6.9 & 7.3 & 8.0 & 7.3 & 7.5 & 8.2 & 7.5 & 8.0 & 8.3 & 8.0 & 8.2 & 8.7 \\
\hline \multirow[t]{3}{*}{200} & 1 & 5.2 & 5.9 & 6.2 & 5.9 & 6.4 & 6.8 & 6.2 & 6.6 & 7.0 & 6.8 & 7.0 & 7.9 \\
\hline & 3 & 6.2 & 6.8 & 7.0 & 6.54 & 7.6 & 7.9 & 6.8 & 8.0 & 8.2 & 7.6 & 8.1 & 8.7 \\
\hline & 5 & 7.1 & 7.4 & 8.2 & 8.2 & 8.4 & 8.91 & 8.3 & 8.5 & 9.0 & 8.6 & 8.8 & 9.1 \\
\hline \multirow[t]{3}{*}{250} & 1 & 6.7 & 6.9 & 7.0 & 6.8 & 7.0 & 7.2 & 7.2 & 7.5 & 7.8 & 7.74 & 7.9 & 8.1 \\
\hline & 3 & 7.3 & 7.9 & 8.2 & 7.8 & 8.08 & 8.4 & 8.2 & 8.4 & 9.0 & 8.9 & 9.1 & 9.4 \\
\hline & 5 & 8.6 & 9.0 & 9.5 & 9.0 & 9.4 & 9.7 & 9.5 & 9.8 & 10 & 9.6 & 10.1 & 10.4 \\
\hline
\end{tabular}


Table.3 Average values of torque force data for different slit cutters at different forward speeds, rotational speeds and depth of cut

\begin{tabular}{|c|c|c|c|c|c|c|c|c|c|c|c|c|c|}
\hline \multirow[t]{2}{*}{$\begin{array}{l}\text { Rot. } \\
\text { Speed }\end{array}$} & \multirow[t]{2}{*}{$\begin{array}{l}\text { Depth } \\
\text { of cut }\end{array}$} & \multicolumn{3}{|c|}{ Trapezoidal } & \multicolumn{3}{|c|}{ Triangular } & \multicolumn{3}{|c|}{$\begin{array}{l}\text { Knife (Full length } \\
\text { sharp) }\end{array}$} & \multicolumn{3}{|c|}{$\begin{array}{l}\text { Knife (Tapered } \\
\text { sharp edge) }\end{array}$} \\
\hline & & 1.0 & 1.5 & 2.0 & 1.0 & 1.5 & 2.0 & 1.0 & 1.5 & 2.0 & 1.0 & 1.5 & 2.0 \\
\hline \multirow[t]{3}{*}{150} & 1 & 14.3 & 13.6 & 13.3 & 14.6 & 13.3 & 13.3 & 13.3 & 13.3 & 13.3 & 13.6 & 13.3 & 13.3 \\
\hline & 3 & 16.6 & 17 & 17.6 & 15.6 & 16.3 & 16.6 & 15.6 & 16 & 16.3 & 16 & 16 & 16.6 \\
\hline & 5 & 18.6 & 19.3 & 19.6 & 18.6 & 18.6 & 18.6 & 18.6 & 18.6 & 19 & 18.6 & 19 & 19 \\
\hline \multirow[t]{3}{*}{200} & 1 & 15 & 15.6 & 16 & 15.3 & 15.6 & 16 & 14.6 & 15 & 15.3 & 14.3 & 14.6 & 15.6 \\
\hline & 3 & 16.3 & 16.6 & 17.3 & 15.6 & 16 & 16.3 & 13 & 16.3 & 17 & 16.6 & 16.6 & 17.3 \\
\hline & 5 & 18.3 & 19 & 19.6 & 17.3 & 17.6 & 18.3 & 18.3 & 18 & 18.6 & 18.3 & 19 & 19 \\
\hline \multirow[t]{3}{*}{250} & 1 & 17.6 & 18 & 19 & 18.3 & 18.3 & 19.3 & 18.3 & 18.3 & 19.3 & 18 & 18.3 & 19.3 \\
\hline & 3 & 19.3 & 20.3 & 20.6 & 18.3 & 18.6 & 19 & 19 & 19.3 & 20.3 & 19 & 19.3 & 20.3 \\
\hline & 5 & 20.6 & 21 & 21 & 19.6 & 19.6 & 20 & 19.3 & 19.6 & 20.6 & 21 & 20 & 20 \\
\hline
\end{tabular}

Table.4 Average values of the width of slit opened data for different slit cutters at different forward speeds, rotational speeds and depth of cut

\begin{tabular}{|c|c|c|c|c|c|c|c|c|c|c|c|c|c|}
\hline \multirow[t]{2}{*}{$\begin{array}{l}\text { Rot. } \\
\text { Speed }\end{array}$} & \multirow[t]{2}{*}{$\begin{array}{l}\text { Depth } \\
\text { of cut }\end{array}$} & \multicolumn{3}{|c|}{ Trapezoidal } & \multicolumn{3}{|c|}{ Triangular } & \multicolumn{3}{|c|}{$\begin{array}{c}\text { Knife (Full length } \\
\text { sharp) }\end{array}$} & \multicolumn{3}{|c|}{$\begin{array}{l}\text { Knife (Tapered } \\
\text { sharp edge) }\end{array}$} \\
\hline & & 1.0 & 1.5 & 2.0 & 1.0 & 1.5 & 2.0 & 1.0 & 1.5 & 2.0 & 1.0 & 1.5 & 2.0 \\
\hline \multirow[t]{3}{*}{150} & 1 & 14.3 & 13.6 & 13.3 & 14.6 & 13.3 & 13.3 & 13.3 & 13.3 & 13.3 & 13.6 & 13.3 & 13.3 \\
\hline & 3 & 16.6 & 17 & 17.6 & 15.6 & 16.3 & 16.6 & 15.6 & 16 & 16.3 & 16 & 16 & 16.6 \\
\hline & 5 & 18.6 & 19.3 & 19.6 & 18.6 & 18.6 & 18.6 & 18.6 & 18.6 & 19 & 18.6 & 19 & 19 \\
\hline \multirow[t]{3}{*}{200} & 1 & 15 & 15.6 & 16 & 15.3 & 15.6 & 16 & 14.6 & 15 & 15.3 & 14.3 & 14.6 & 15.6 \\
\hline & 3 & 16.3 & 16.6 & 17.3 & 15.6 & 16 & 16.3 & 13 & 16.3 & 17 & 16.6 & 16.6 & 17.3 \\
\hline & 5 & 18.3 & 19 & 19.6 & 17.3 & 17.6 & 18.3 & 18.3 & 18 & 18.6 & 18.3 & 19 & 19 \\
\hline \multirow{3}{*}{250} & 1 & 17.6 & 18 & 19 & 18.3 & 18.3 & 19.3 & 18.3 & 18.3 & 19.3 & 18 & 18.3 & 19.3 \\
\hline & 3 & 19.3 & 20.3 & 20.6 & 18.3 & 18.6 & 19 & 19 & 19.3 & 20.3 & 19 & 19.3 & 20.3 \\
\hline & 5 & 20.6 & 21 & 21 & 19.6 & 19.6 & 20 & 19.3 & 19.6 & 20.6 & 21 & 20 & 20 \\
\hline
\end{tabular}

Fig.1 Developed rotary zero-till-slit seed drill

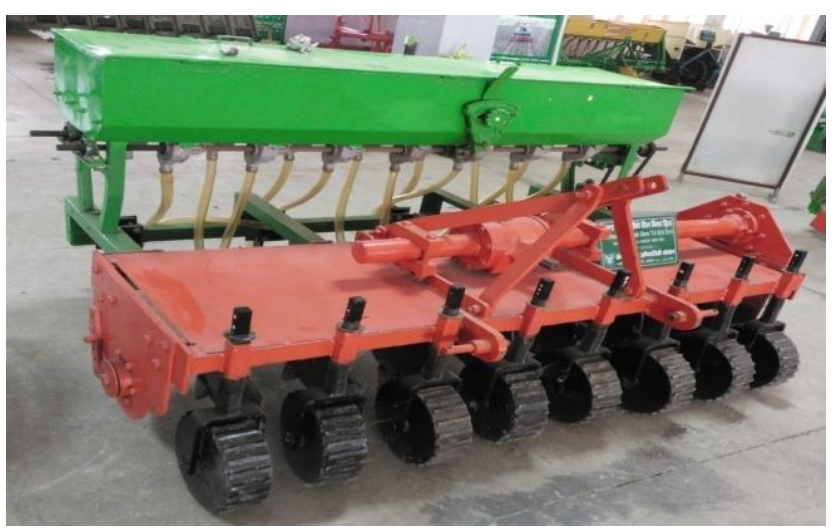


Fig.2 Slit cutters mounted on common shaft

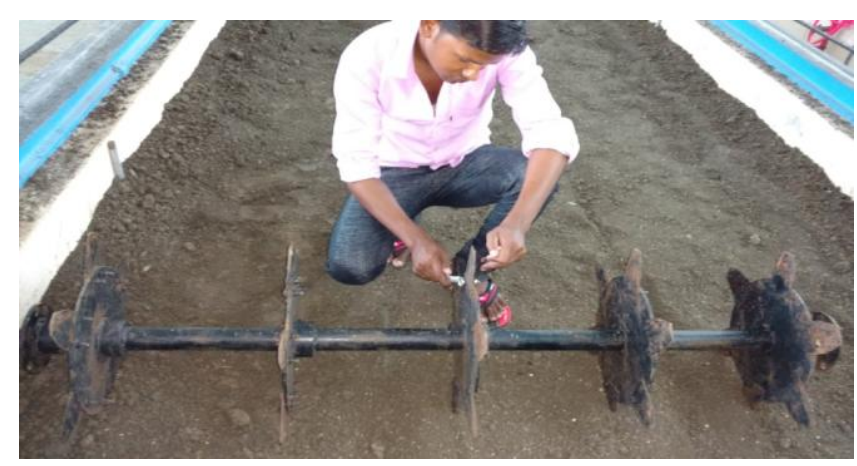

Fig.3 Slit cutter blade of trapezoidal shape with flange
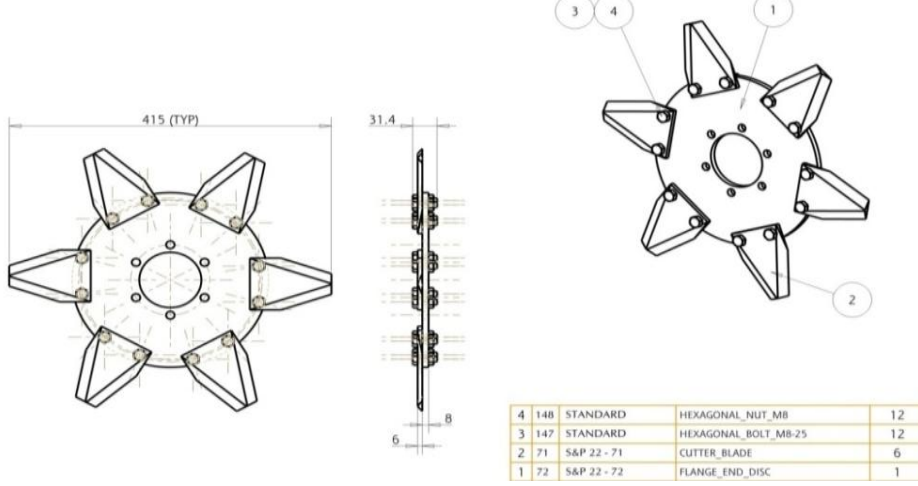

Fig.4 Slit cutter blade of triangular shape with flange
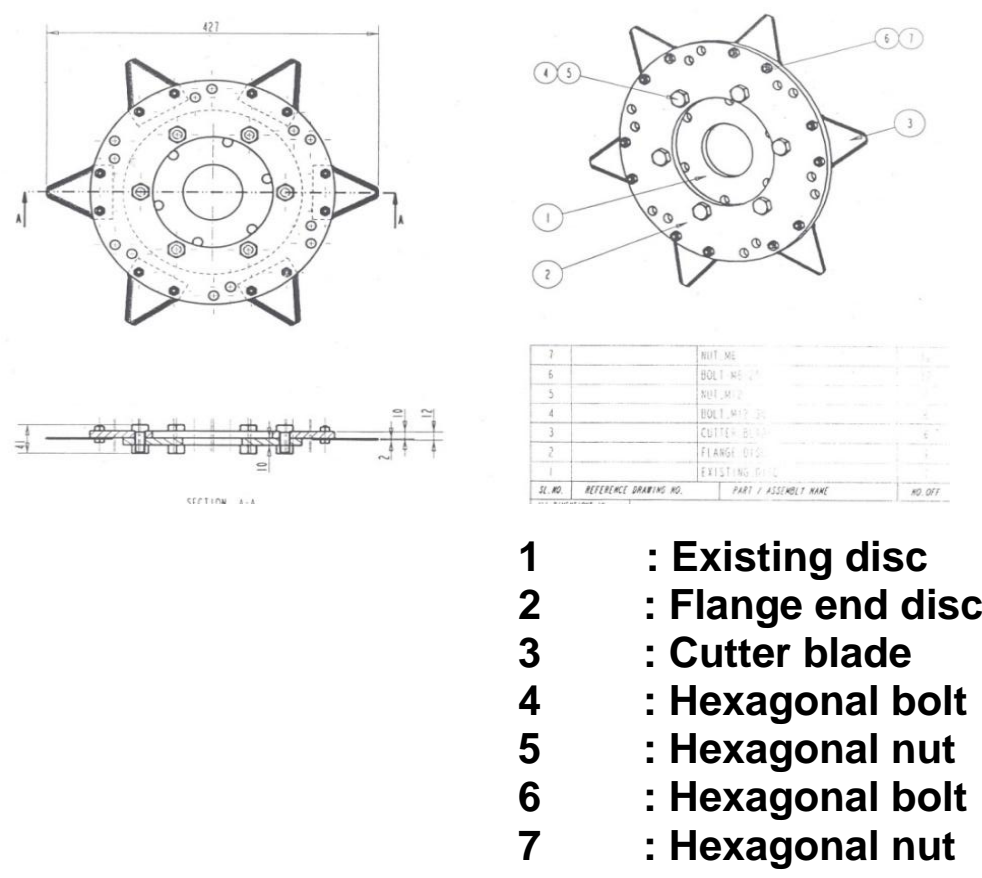
Fig.5 Knife shape (full-length sharp edge) slit cutter blade
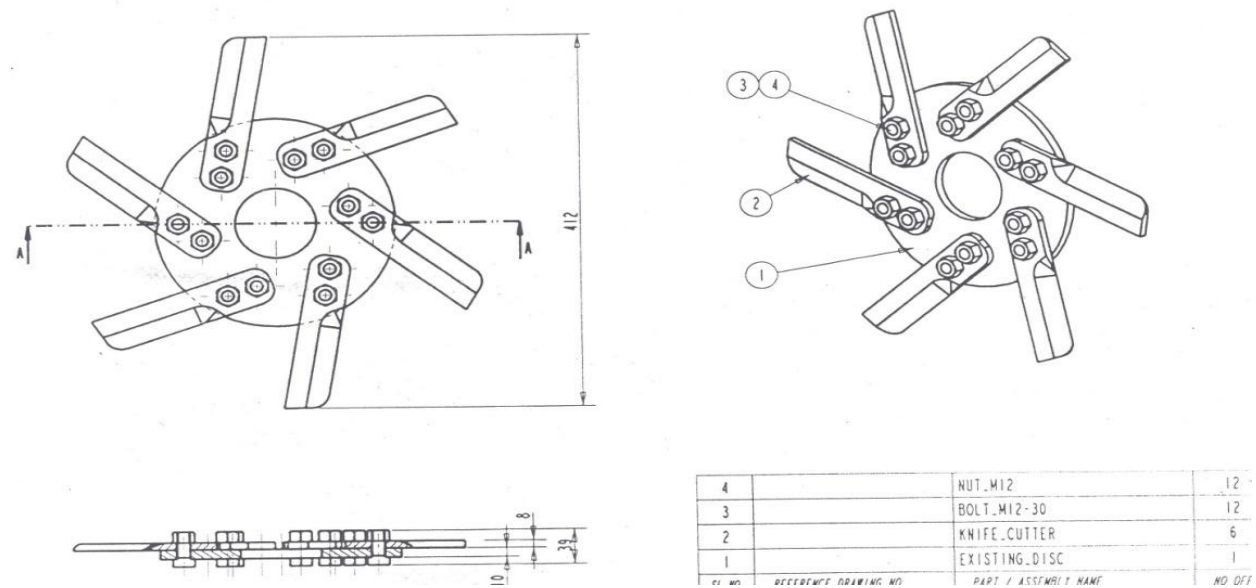

\section{1 : Existing disc \\ 2 : Knife cutter blade \\ 3 : Hexagonal bolt \\ 4 : Hexagonal nut}

Fig.6 Knife shape (pointed tip, tapered edge) slit cutter blade
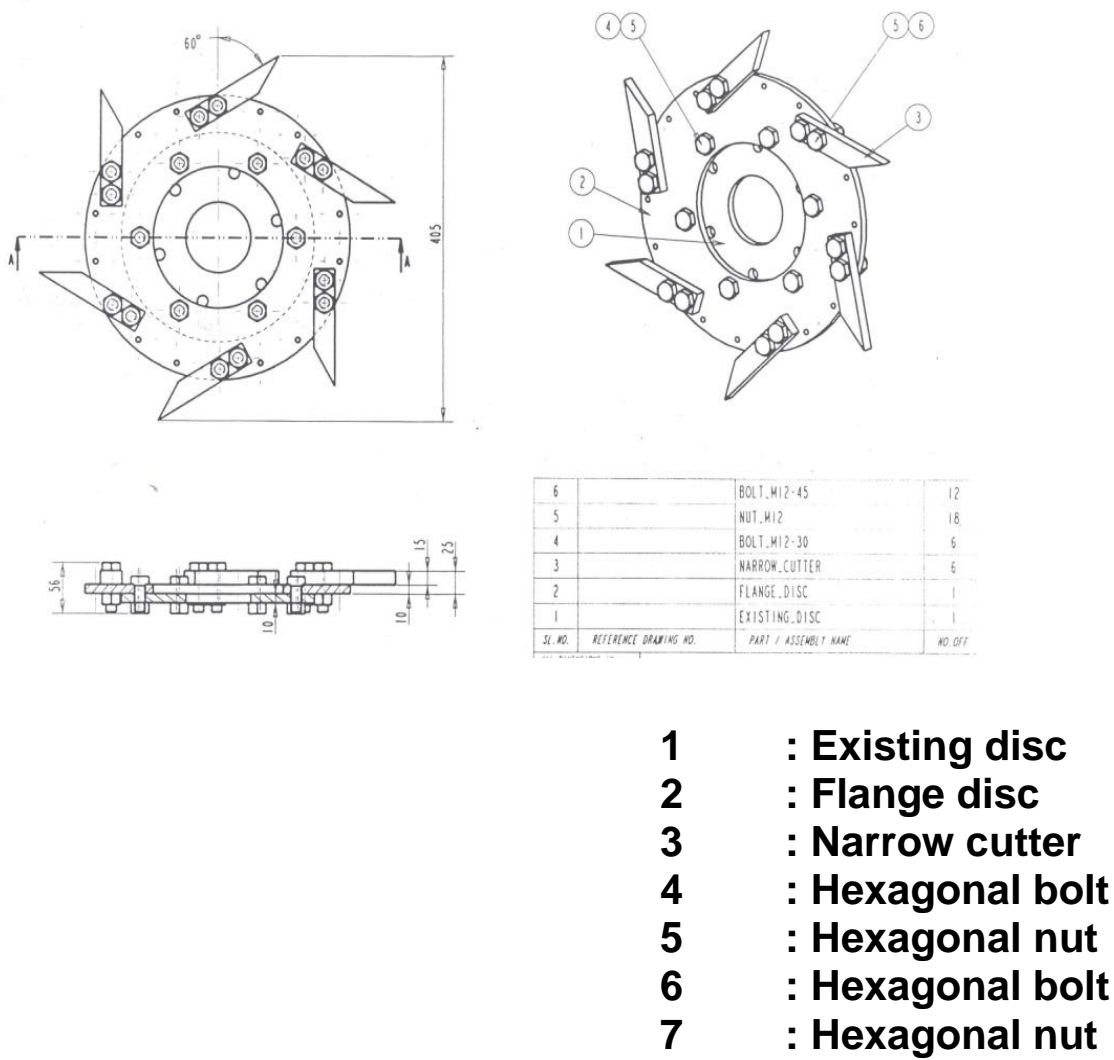
Fig.7 Soil-bin facility at CIAE, Bhopal

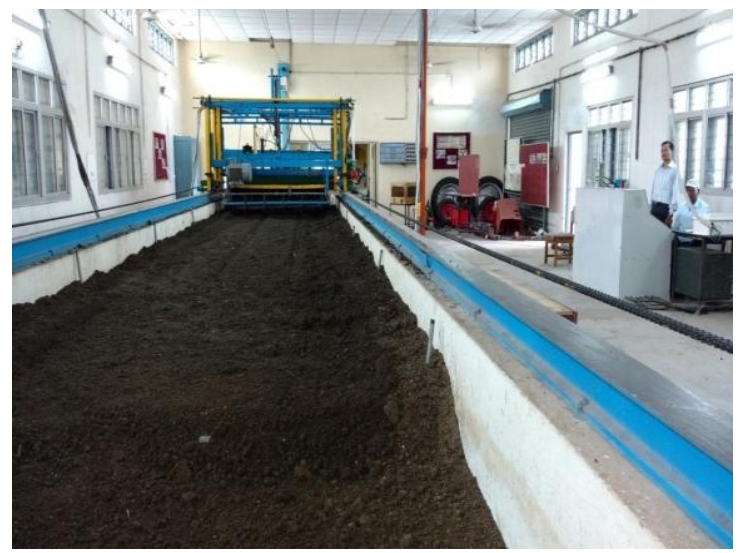

Fig.8 Tool and instrumentation carriage

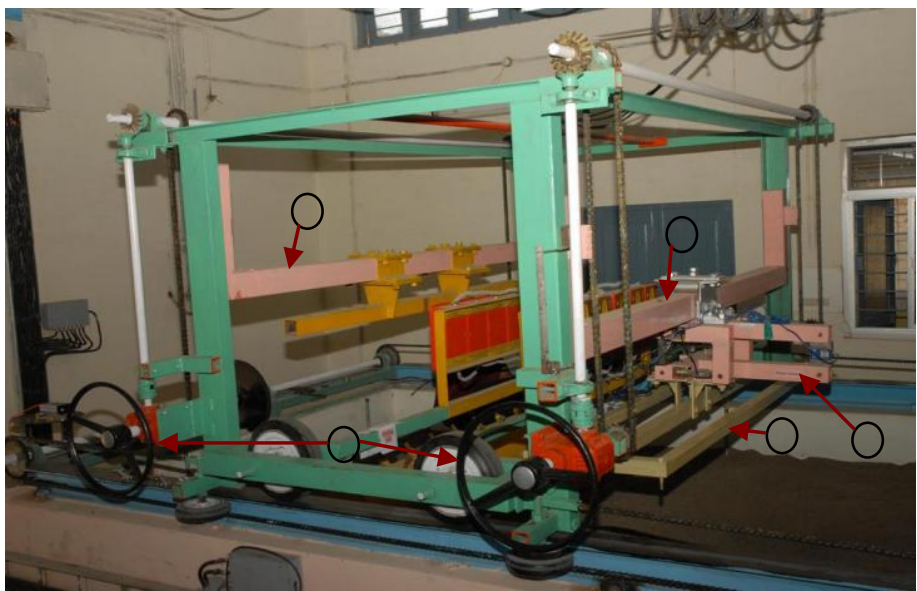

Figure 8: Tool and instrumentation carriage

Fig.9 Operation of soil-bin from the control panel

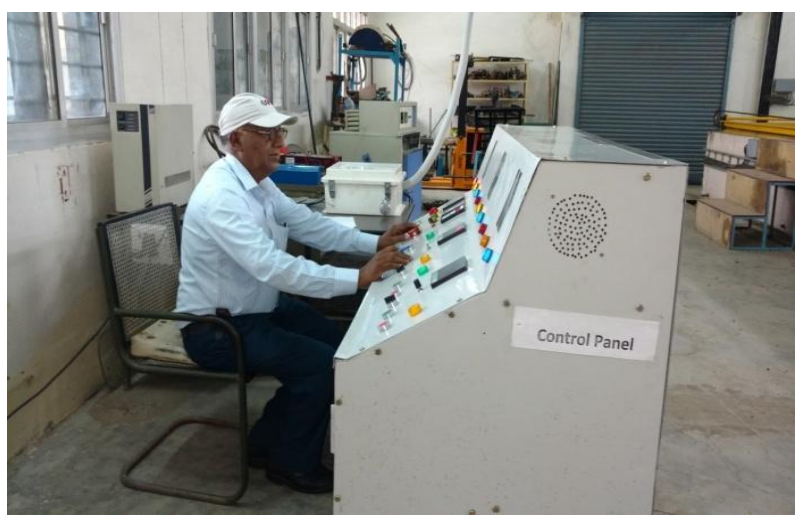


Conclusions are as follows:

Lower values of horizontal force $(\mathrm{N})$, vertical force $(\mathrm{N})$ and torque exerted $(\mathrm{N}-\mathrm{m})$ were found in the trapezoidal section of slit cutter compared to triangular section, knife section with full-length sharp edge and knife section with a pointed tip and tapered sharp edge.

A horizontal force $(\mathrm{N})$, vertical force $(\mathrm{N})$ and torque exerted $(\mathrm{N}-\mathrm{m})$ were found increased as forwarding speed (S), rotational speed (RS) and depth of cut of slit cutter blade increases in the four shapes of rotary blade slit cutters.

The width of slit cut $(\mathrm{mm})$ were found decreased as forwarding speed of slit cutter blades increases in the four blade sections of rotary slit cutters. The width of the slit cut $(\mathrm{mm})$ was also found increased as the rotational speed increases and depth of cut of blades increases in the four blade sections of the rotary slit cutter.

The effect of blade shape of slit cutter (C), forward speed (S), rotational speed (RS) and depth of cut (d) on the horizontal force, vertical force, torque exerted and width of slit cut were found highly significant.

Four shapes of slit cutter blades were designed, developed and evaluated for use in the zero-till-slit seed drill namely trapezoidal sharp edge, triangular serrated, full-length sharp edge knife section and knife section with a pointed tip and tapered sharp edge. The blades were mounted on a common shaft with the help of flanges. The trapezoidal section slit cutter blade exerted lower horizontal force, vertical force, the torque exerted and opened more wide slits. Based on the performance of the four rotary blades /knives in soil bin, performances of trapezoidal shape slit cutter with a sharp edge was found to be advantageous in cutting/chopping of surface straw, depth and width of slits opened in zerotill soil compared to other blades/knifes section tested.

\section{References}

Anonymous, (2202) Irrigated agroecosystems: Progress report for MidTerm review, National Agricultural Technology Project, Directorate of Maize Research, I.C.A.R., New Delhi, pp 11-12.

Chaudhary, VP., and Singh B., 2002. Effect of zero, strip and conventional tillage system on performance of wheat. Journal of Agricultural Engineering, 39 (2): $27-31$

Fiszer, A., Dworecki Z., Kazmierczak P and Morkouski A. 2007. Comparative analysis of traditional and plough less cultivation of winter wheat. Agricultural Engineering Abstracts, 32 (2).

Singh, RD., and Singh PM. 2006. Performance of zero-till drill for lentil cultivation at farmer's fields. Journal of Agriculture engineering, 43(1): 3537.

\section{How to cite this article:}

Mohammad Quasim, A.K. Shrivastava, S.K. Rautaray and Avinash Kumar Gautam. 2019. Development and Evaluation of Different Rotary Slit Cutters under Controlled Condition. Int.J.Curr.Microbiol.App.Sci. 8(05): 13-23. doi: https://doi.org/10.20546/ijcmas.2019.805.003 